\title{
Structural Changes in the Agro-Industrial Complex of the Region as a Factor in Ensuring Food Security in the Transition to an Information Economy
}

\author{
Minin D.L. \\ Yaroslav-the-Wise Novgorod State University, \\ Veliky Novgorod, Russia, \\ dmitryminin@mail.ru
}

\author{
Minina E.S. \\ Yaroslav-the-Wise Novgorod State University, \\ Veliky Novgorod, Russia, \\ Elena.Minina@novsu.ru
}

\author{
Minin I.L. \\ Yaroslav-the-Wise Novgorod State University, \\ Veliky Novgorod, Russia, \\ Ivan.Minin@novsu.ru
}

\begin{abstract}
The article presents the results of studies of changes in the agro-industrial complex of the region as a factor in ensuring food security in the context of the transition to an information economy. The main theoretical and methodological approaches to the problems of the development of branches of the agro-industrial complex in the context of a dynamically changing economic and social structure in the context of sanctions and the consequences of the global COVID-19 pandemic have been investigated. The authors presented recommendations for ensuring the progressive development of the branches of the regional agro-industrial complex in the medium and long term. The forecast of the structure of consumption of the main types of agricultural products by the population of the main groups of countries of the world until 2030 is presented. The article presents calculations that indicate the dynamics of production of the main types of agricultural products, which provide a basis for the possibilities of further research in this direction. The promising directions for the development of livestock production in the regions have been determined. The key problems of maintaining the stable growth of crop and livestock industries in the regional agro-industrial complex, as well as processing and supporting industries, are highlighted. Recommendations are formulated to ensure the progressive development of the branches of the agro-industrial complex to ensure food security in the context of the transition to an information economy in the context of a global pandemic and the necessary development of territorial complexes of the agroindustrial complex.
\end{abstract}

Keywords-Agro-industrial complex, livestock, information economy, food security, crop production, structural changes

\section{INTRODUCTION}

The ongoing changes in all sectors of the economy, both in connection with the processes of transition to a new economic formation, and in connection with the pandemic and the exacerbation of issues of regional food security, cause the accelerated transition of the relevant sectors to a new economic order [1].

The changes in the processes of production and consumption of food products are also significantly influenced by the ongoing adaptation of the economy in the information environment [2]. The changes affect all branches of entrepreneurship, including the branches of the regional agroindustrial complex [3]. Over the past decade, significant changes have taken place in the branches of the regional agroindustrial complex [4]. These changes were caused by changes in the structure of consumption of agricultural products. As well as a significant change and development of the complex was influenced by the economic sanctions imposed by foreign states. This significantly accelerated the development of the regional sector and led to the full provision of food security in most constituent entities of the Russian Federation. Which could not have happened without the implementation of structural changes in the branches of the regional agroindustrial complex.

\section{PROBLEM STATEMENT}

The agro-industrial complex in Russia is rather conservative. Significant changes in the structure of industries usually occur spontaneously, under the influence of significant external factors. 
The existing processes of functioning of the branches of the agro-industrial complex indicate the presence of problems in the field of effective management, carrying out complex projects together with other enterprises and ensuring interaction that can increase the efficiency of the development of the corresponding industries in the territory of the country [5]. In addition, in the context of sanctions and quarantine restrictions due to the global epidemic, enterprises have faced problems in the sale of products and the reorientation of production to domestic components. This made it much more difficult to maintain the pace of planned development and ensure the proper level of food security in a changing economic formation [6].

\section{RESEARCH QUESTIONS}

Currently, measures are being taken to further develop the branches of the regional agro-industrial complex, as the main factor in ensuring regional food security. As part of the development of the regional economic formation and the processes of development of self-sufficiency in regions, as the main factor of development in the medium term in the context of a global pandemic and the disruption of existing economic ties, both under the influence of sanctions and the adopted quarantine measures, support for the agro-industrial complex has increased [7]. Among the support measures, one can single out government support measures, including reducing the tax burden, providing guarantees and preferential lending, deferring rental payments, suspending inspections until 2022, etc. Despite the measures taken in the industry, there are still problems, without the solution of which it becomes impossible to further progressive development and ensure food security in the information economy.

\section{PURPOSE OF THE STUDY}

The purpose of the study is to identify problems and find ways and measures for the development of branches of the regional agro-industrial complex as a factor in ensuring food security in the transition to an information economy.

In accordance with this goal, it seems important to study the main indicators of the sectors of the agro-industrial complex in order to identify key trends and changes [8]. An important element will also be the identification of factors restraining the development of the industries of the complex, the determination of the most relevant development directions, taking into account modern economic realities and the formation of development prospects in the post-quarantine period in the context of the development of the digital economy and changes in the consumption patterns of the main types of products in the medium term.

\section{RESEARCH METHODS}

The study is based on the generalization of the research carried out by foreign and domestic scientists and economists in the field of functioning of the agro-industrial complex and ensuring food security. In the course of the study, methods based on the processes of analyzing statistical data and empirical forecasting methods were used. The research results are formulated by the authors on the basis of reliable data of advanced scientific economic thought, indicators of official statistics [9-13].

\section{RESULTS}

Based on the data of official statistics [12], we will consider the main directions of consumption of agricultural products by countries of the world in order to highlight the main trends (Fig. 1).

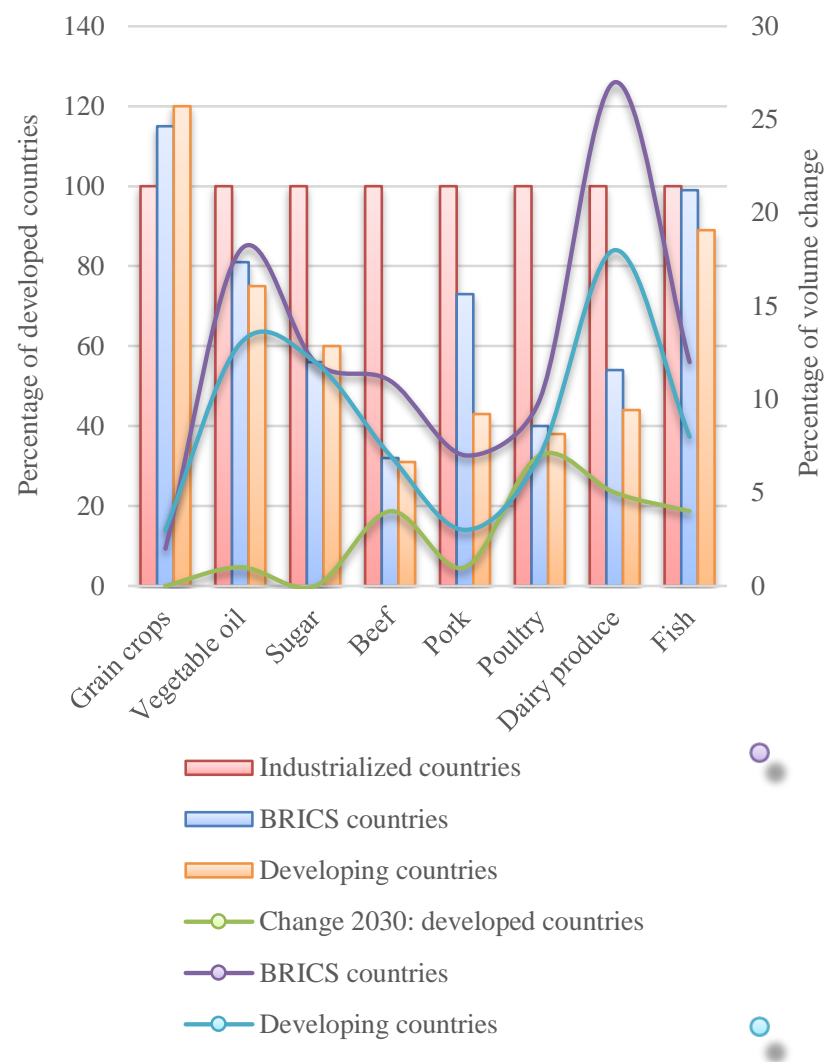

Fig. 1. Forecast of changes in the consumption of agricultural products by countries of the world for $2030(\%)$ (according to [8, 12])

The presented graph of the adjusted forecast of the consumption of agricultural products by the countries of the world for 2030 shows that promising directions of development in the structure of consumption are such products as grain, vegetable oil, dairy products, sugar, fish. In recent years, Russia has been increasing its presence in the world food market in the production of milk and dairy products. The growth potential is $5 \%$ for developed countries, $27 \%$ for BRICS countries and $18 \%$ for developing countries of the world [12]

To determine the promising directions for the development of industries, we will analyze the data on the volume of the commodity structure of agricultural exports in Russia in 2019 amounted to 10.04 billion dollars. In the structure of exports of the national economy, grain dominates - 6294 million dollars, while other types still have a modest weight. In 2019, exports of fish and seafood, excluding processed products, amounted to 3.23 billion dollars excluding goods registered outside of customs [12].

Most of the imported food products are meat and meat products, fruits, vegetables, fish and fish products. The decrease in imports to Russia in 2019, as in the previous year, is due to the import substitution program that has been implemented in the country since 2015. As a result of the measures carried out by the Government of the Russian 
Federation on import substitution in 2019, the volume of imports of livestock products decreased by $8 \%$ [12].

According to the forecast of the government of the Russian Federation, in 2021 it is planned to reduce the import of food products by the main categories of import substitution products. For these purposes, the state put into operation production facilities specializing in the production of products not typical for Russia.

In the context of the reorientation of the economy towards integrated territorial development, we will consider the structure of production in the context of the federal districts of animal husbandry (Fig. 2) and crop production (Fig. 3).

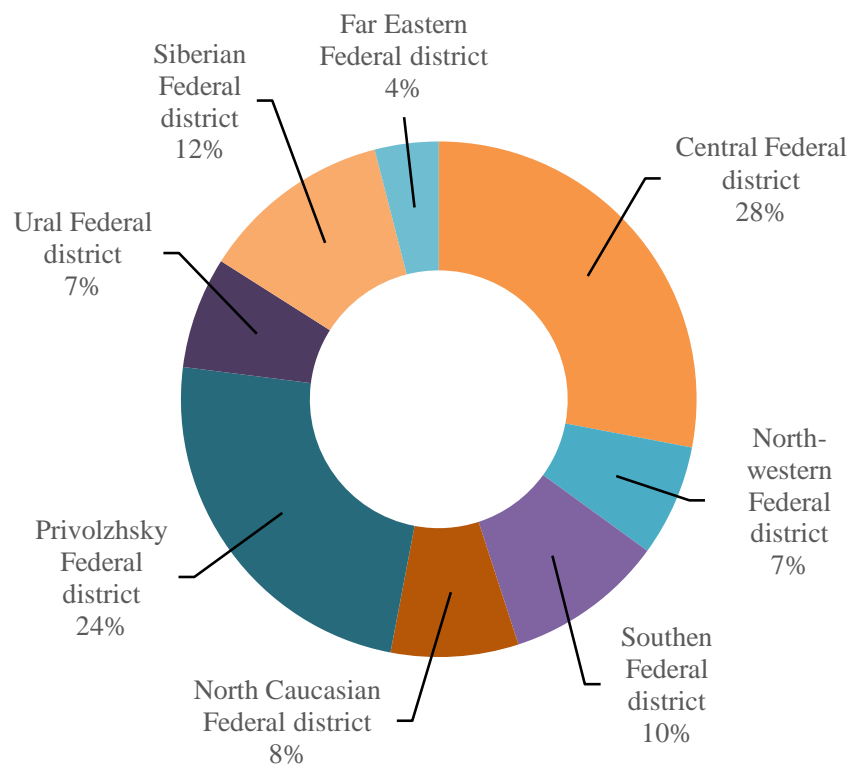

Fig. 2. Livestock products in 2019 in the context of federal districts (according to [12])

The presented data on the structure of production indicate the uneven development of the agro-industrial complex in the territorial context. Having studied the dynamics of the production of key types of products by regions of the Russian Federation over the past five years, it can be concluded that in 2019-2020, a comprehensive development of the production of all types of agricultural products began in most regions of the Russian Federation.

An additional catalyst for development was the processes taking place in 2020 associated with the restructuring of regional economies and an orientation towards complete import substitution. Including through the development of high-tech industries of certain types of agricultural products.

Significant shifts were observed in areas with an active investment potential, as well as in those territories where state / regional support was actively promoted in the form of subsidies and grants for the development of specific areas of the agro-industrial complex.

An example is the Nizhny Novgorod region, which in 2018-2019 significantly increased the production of crop products thanks to active investment and the use of advanced technologies for the production of crop products. The complex use of advanced developments, as well as the geographic location, allows the territories of the Central and Volga districts to hold the lead.

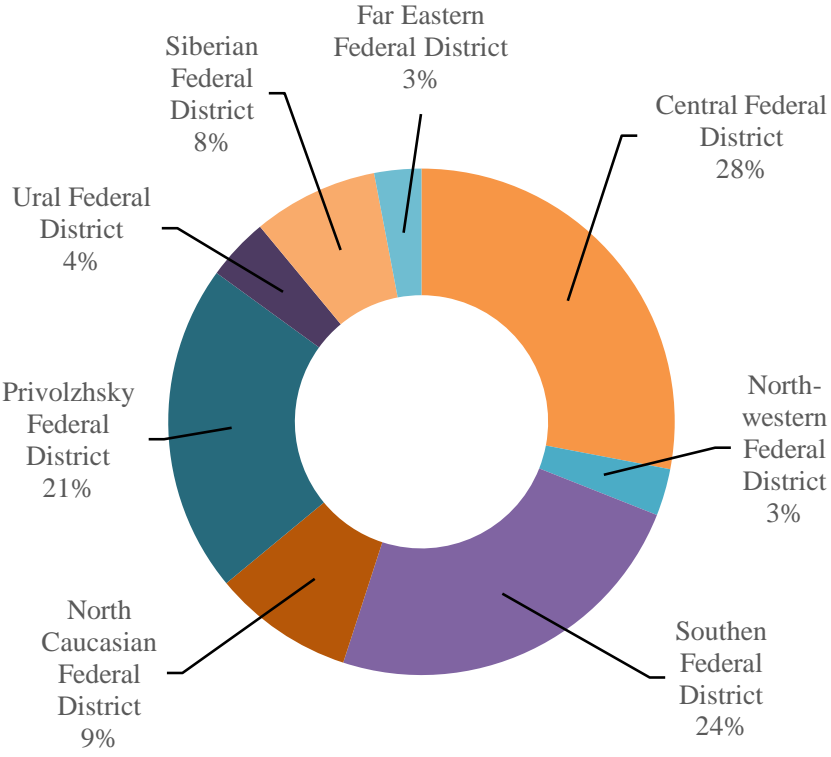

Fig. 3. Crop production in 2019 in the context of federal districts (according to [12])

The incoming data on the development of regional agricultural production indicate the beginning of the active development of livestock production: the production of fresh milk and dairy products, cattle meat, poultry. But the presented positive dynamics is observed in those regions and municipalities where state support in the form of grants ("agro-start-up" and similar programs) is actively promoting.

Increasing requirements for the quality of products, improving the living standards of the population, ensuring employment in rural areas create a positive sales market for environmentally friendly agricultural products.

Studies have shown that in order to ensure the strategic development of the production of products of the agricultural sector, taking into account the changes in the world market and the reorientation of regional complexes towards complete self-sufficiency of the territories, it is necessary to comprehensively implement the following recommendations.

1) To ensure the attraction of investments in the agricultural sector, more than 4-6\% of GDP of the existing level of industry support. At present, due to a lack of equipment, a significant part of arable land is not cultivated (more than 30-40\% in certain regions), in some regions there are only 2-3 tractors per 100 hectares of arable land. Due to low profitability, livestock breeders are forced to reduce the number of cattle, which leads to an increase in meat imports.

2) To solve problems with transportation and storage of agricultural products comprehensively; to set high prices for fuels and lubricants. Depending on the type of crops, more than $40 \%$ of products are spoiled during transportation and storage. In practice, due to the large territory of Russia, problems arise with the redistribution of agricultural products. There are similar situations at the regional level, when in some regions there is a significant surplus of certain types of products, and in others, due to problems with logistics, transportation and processing, there is a shortage of relevant goods. 
3) To solve the strategic personnel problem. Ensuring the attraction of highly qualified personnel, since low wages and difficult working conditions increase the outflow of workers from the branches of the regional agro-industrial complex, as well as a low level of scientific support; the introduction of the latest achievements of scientific and technological progress in the functioning of the agricultural sector of the economy negatively affects the pace of development.

4) To actively implement the "innovative option for the development of agriculture", which is based on the support of the innovation and investment sector; improving the sectoral structure of the agro-industrial complex economy by accumulating scientific and technical potential and creating a stable investment climate for agriculture and manufacturing industry at the expense of enterprises' own sources, attracting foreign and federal funds, increasing research and development costs, modernizing interconnected sectors of the economy [16]. The scenario of the innovative development of agriculture, along with the use of competitive advantages, implies an increase in the efficiency of human capital and the development of high- and medium-tech full cycle production; characterized by higher parameters of import substitution and innovative activity of companies.

\section{CONCLUSION}

The ongoing changes in the structure of world consumption of basic agricultural products led to an accelerated transition of the branches of the regional agroindustrial complex to a new type of activity based on the more active use of products of the information economy in production and marketing processes [16].

The methods of state support of agricultural enterprises applied in recent years have allowed gaining a good pace of development, and ensuring almost $100 \%$ level of import substitution, and $95-98 \%$ food security of the territories. The existing problems are largely caused by the processes of combating the pandemic, and although they are temporary in nature, they have significantly complicated the processes of operation of the agro-industrial complex, due to the appearance of a number of restrictions [17]

From which it follows that in order to ensure constant growth and development of territories, it is necessary to actively support the development of the agro-industrial complex in terms of the production of environmentally friendly products, its promotion to external markets in relation to the territory, the region [18].

To stimulate the involvement of representatives of small and medium-sized businesses in production processes in order to ensure differentiation and availability of products throughout the territory of the constituent entities of the Russian Federation. To develop not only the production and sales infrastructure, but also to provide positive information support to the participants in the production process of the regional agro-industrial complex.

\section{References}

[1] A.V. Glushchenko, G.V. Fedotova, N.V. Gryzunova, S.S. Sultanova and V.M. Ksenda, "Modernization of the Russian Agro-Industrial Complex in the Conditions of Increase of Food Security", Lecture Notes in Networks and Systems, Springer, Cham, 2020, vol. 87 pp. 3-12. (In Russ.). DOI: https://doi.org/10.1007/978-3-030-29586-8_1

[2] E.G. Popkova, "Contradiction of Economic Growthin Today's Global Economy", Economic Systems Competition and Mutual Support. Espacios, 2018, vol. 39(1). (In Russ.). Retrieved fromhttp://www.revistaespacios.com/a18v39n01/a18v39n01p20.pdf

[3] M.M. Omarov, N.Yu. Omarova and D.L. Minin, "Territory branding development as a regional economy activation factor", Lecture Notes in Networks and Systems, Springer, Cham, 2020, vol. 87, pp. 270-277. (In Russ.). DOI: https://doi.org/10.1007/978-3-030-29586-8_32

[4] V. Plotnikov, G.V. Fedotova, E.G. Popkova and A.A. Kastyurina, "Harmonization of Strategic Planning Indicators of Territories' Socioeconomic Growth", Regional and Sectoral Economic Studies, 2015, vol. 15(2), pp. 105-114. (In Russ.). Retrieved from http://www.springer.com/gp/book/9783319606958\#otherversion=97833 19606965

[5] J. Shumpeter, "Theory of Economic Development" ["Teoriya ekonomicheskogo razvitiya"]. Moscow: Progress, 2016. (In Russ.)

[6] J.A. Allen, "Scientific Innovation and Industrial Prosperity", London, 2016.

[7] S. Echchakoui, "Effect of salesperson personality on sales performance from the customer's perspective: Application of socioanalytic theory", European Journal of Marketing, 2017,vol. 51(9/10), pp. 1739-1767. DOI: https://doi.org/10.1108/EJM-03-2016-0147

[8] M.M. Omarov, N.Yu. Omarova and D.L. Minin, "World trends and strategic prospects for the development of Russian agriculture under the conditions of economic sanctions", in Yu.G. Lavrikova and V.P. Neganova (Eds.), The food market of the Russian Regions: A new development vector, Ekaterinburg: Ural Branch of RAS, 2018, (pp. 1729). (In Russ.).

[9] P. Drucker, "Innovation and Entrepreneurship",Routledge, 2016.

[10] E.M. Akishina, E.N. Piryazeva, "Contemporary Digital Art As A Factor In The Creative Development Of Personality", in European Proceedings of Social and Behavioural Sciences EpSBS, 2019. (In Russ.). DOI: https://doi.org/10.15405/epsbs.2019.09.02.1

[11] C. Freeman, "The Economics of Industrial Innovation", London Penguin. 2015.

[12] Federal State Statistics Service 2020. Retrieved from http://www.gks.ru

[13] A. Hein, M. Schreieck, T. Riasanow, D.S. Setzke, M. Wiesche, M. Böhm and H. Krcmar, "Digital platform ecosystems", Electron Markets, 2020, vol. 30, pp. 87-98. DOI: https://doi.org/10.1007/s12525019-00377-4

[14] D.G. Bottrelland K.G. Schoenly, "Integrated pest management for resource-limited farmers: Challenges for achieving ecological, social and economic sustainability", The Journal of Agricultural Science, 2018, vol. 156(3), pp. 408-426. DOI: https://doi.org/10.1017/S0021859618000473

[15] N. Sammanand and R. Charrondiere, "From food composition to better policies and programmes in nutrition and agriculture", in Proceedings of the12th International Food Data Conference (IFDC), Journal of Food Composition and Analysis, 2020, vol. 90, 103490.

[16] D.L. Minin, "Investment's features in order to ensure sustainable development in the longterm", in the European Proceedings of Social andBehavioural Sciences EpSBS, CIEDR 2018 (Future Academy), 2019, pp. 579-589 (In Russ. https://doi.org/10.15405/epsbs.2019.04.62

[17] L.A. De los Santos-Montero, B.E. Bravo-Ureta, S. von CramonTaubadel and E. Hasiner, "The performance of natural resource management interventions in agriculture: Evidence from alternative meta-regression analyses", Ecological Economics, 2020, vol. 171.

[18] E. Bolandnazar, A. Rohani and M. Taki, "Energy consumption forecasting in agriculture by artificial intelligence and mathematical models", Energy Sources Part a-Recovery Utilization and Environmental Effects, 2020, vol. 42(13), pp. 1618-1632. 